\title{
NARRATIVAS NA PANELA DE BARRO. A ACADEMIA DO PEIXE FRITO EM JAQUES FLORES
}

\section{RESUMO}

O presente artigo tem como objetivo enfatizar o papel do escritor paraense Luís Teixeira Gomes, Jacques Flores, a partir do texto "Vamos comer peixe frito?" que integra a coletânea "Panela de Barro", livro publicado em 1947. Busca-se compreender os traços da crônica de Jaques, que era marcada pela força da realidade local, com tipos humanos crenças e costumes da população de Belém, dentre as quais está o costume de "comer peixe frito". No texto em questão, através de um estudo biobibliográfico e descritivo, investigamos uma hipótese de representação do nome de um grupo de intelectuais, a geração peixe frito, e sua representatividade no cenário sociocultural e político de Belém, a partir dos anos 30 do século XX.

Palavras-chave: Jaques Flores; Academia do Peixe Frito; narrativa; Panela de Barro.

\begin{abstract}
The purpose of this article is to emphasize the role of the Paraense writer Luis Teixeira Gomes, Jacques Flores, from the text "Let's eat fried fish?" That integrates the collection "Clay pot", a book published in 1947. It seeks to understand the features of the Jaques, who was marked by the strength of local reality, with human types beliefs and customs of the population of Belém, among which is the custom of "eating fried fish". In the text in question, through a bio-bibliographic and descriptive study, we investigated a hypothesis representation of the name of a group of intellectuals, the generation of fried fish, and their representativeness in the sociocultural and political scenario of Belém, from the 30's of the twentieth century.
\end{abstract}

Keywords: Jaques Flores. Fried Fish Academy. Narrative. Clay pot. 


\section{O NASCIMENTO DO HOMEM}

No dia 10 de julho de 1893, em Belém, Jaques Flores nasceu Luís Teixeira Gomes, filho de João Teixeira Gomes e Antônia da Conceição Gomes; de origem humilde, ainda jovem teve de começar a trabalhar, quando precocemente ficou órfão de pai. Tendo de parar de estudar, ele iniciou sua vida profissional numa oficina gráfica como tipógrafo, o que acabou despertando o jornalista e posteriormente o prosador e o poeta que existiam dentro de si.

O jornalista Georgenor Franco, no texto "Luis Teixeira Gomes: se mudasse deixaria de ser Jaques Flores", assim finaliza sua reportagem sobre o autor: "Poeta, cronista, ensaísta e jornalista, em todas as profissões foi um homem consciente de suas responsabilidades e um constante animador e entusiasta de tudo quanto se relacionasse com a cultura e a arte do Pará".

Jaques Flores atuou no jornal Folha do Norte, era muito respeitado no meio jornalístico por seu estilo claro expressivo e ainda por sua seriedade profissional, pois, como jornalista fez centenas de crônicas, exercendo extraordinário senso crítico a respeito de tudo o que o rodeava. Foi autor também de conferências e trabalhos avulsos, publicados ao longo da vida.

Fig. 1. Fonte: https://acervodagraphia.wordpress.com/ category/jaques-flores/. Acesso em: 17/03/2018

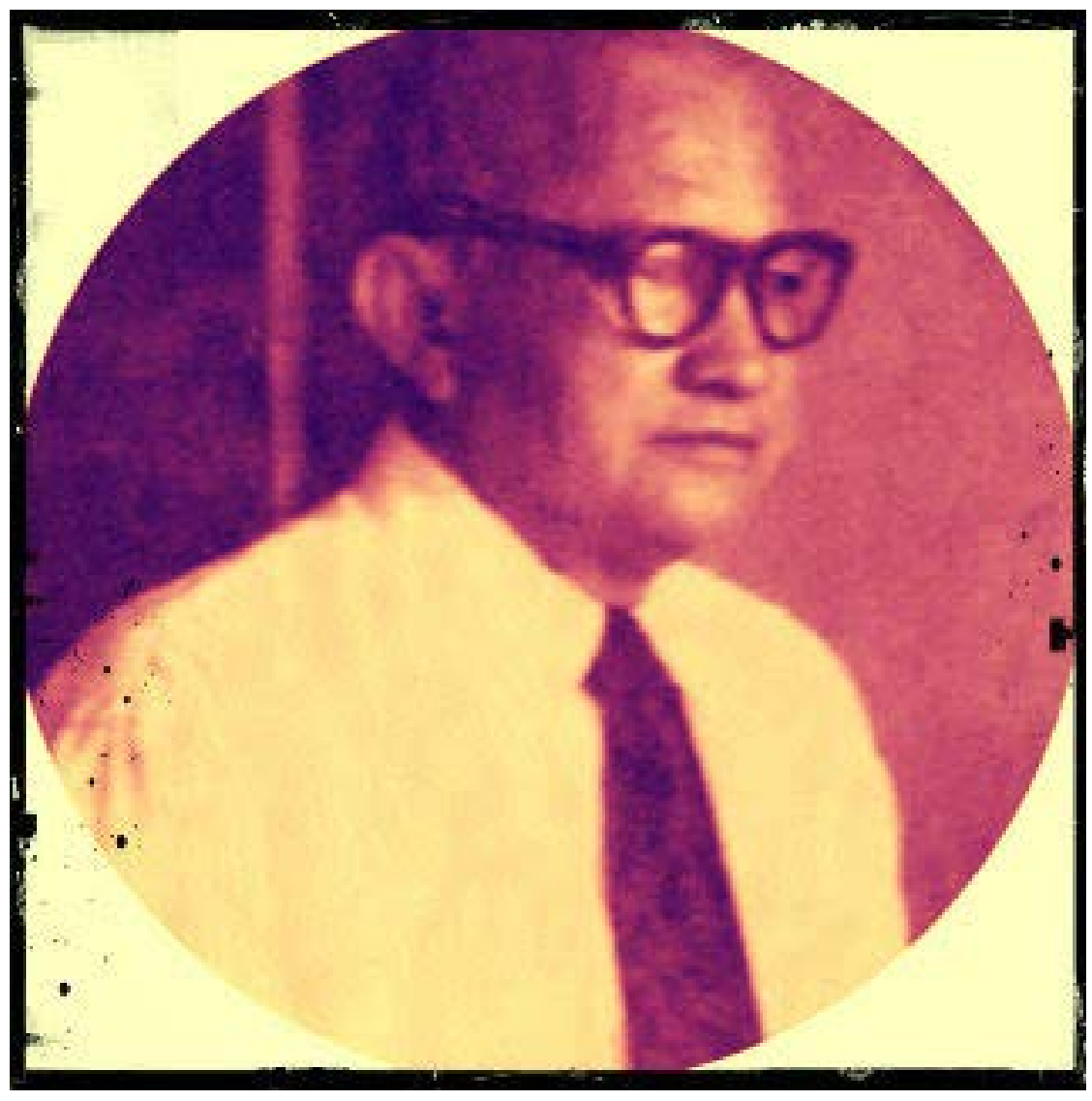

\section{JAQUES FLORES, O "MANDAUÊRA"}

Luís Teixeira Gomes quis nascer Jaques Flores, pseudônimo escolhido pelo do escritor para assinar sua obra, que tinha como característica um toque especial de humorismo, provavelmente o traço mais marcante de sua escrita, o que proporcionou destaque em suas narrativas e chamava atenção de seus leitores. Sua escrita singular, experiência advinda da prática do jornalismo, fez de Jaques Flores um grande cronista, homem de notável poder de observação, ele era um atento perscrutador do cotidiano da cidade, do povo que a habitava com seus costumes e crenças. 
Chama atenção, na apresentação que fez do livro Panela de Barro (1947), o destaque dado Abguar Bastos a Jaques Flores, "um contador de histórias”, guardador das tradições:

Jaques Flores publica mais um de seus livros regionais, Vai contando, como numa conversa, as coisas que se passam na Amazônia, as próprias coisas da Amazônia(...) Conta essas maneiras de viver, de trabalhar, de produzir, de manter o pitoresco numa sociedade entre civilizada e primitiva, conforme se avance do litoral para a cabeceira dos rios (...). É um autêntico maranduêra- aquele eu guardava as tradições de nossas tribos.

Eis uma boa síntese que não pode ser desconsiderada: um guardador das tradições paraenses. Jaques Flores não deixava passar despercebidos aspectos da sociedade de sua época, que lhe chamassem atenção e por isso, em seus textos ele narrava o cotidiano com seu toque peculiar de humor que, segundo Georgenor Franco, fez Augusto Meira compará-lo a Emílio de Menezes, paranaense imortal da Academia Brasileira de Letras, mestre de textos satíricos.

Jaques participou da renovação desencadeada pelo movimento modernista no Pará, atuando intensamente na "Associação dos Novos" e cooperando com Bruno de Menezes na revista "Belém Nova". O Modernismo conduziu-o à utilização intensiva do linguajar caboclo, permeando de regionalismos toda a sua obra, tanto na poesia quanto na prosa. Sobre este período, Abguar Bastos afirma ainda na apresentação do livro Panela de Barro:

Entre 1920 e 1930, éramos 15 rapazes unidos no bom combate aos tabus e a tirania acadêmica, aos falsos preconceitos de classe. Investíamos sem cerimônia contra os lideres literários do tempo e em seguida nossa luta estava transformada, não só numa batalha pela democratização da arte, por uma arte livre e simples, como pela democratização política, por uma liberdade mais real, mais digna.

O que destacava neste grupo de rapazes, prossegue Abguar Bastos, era a sua união, sua incansável fraternidade, o seu amor recíproco e fraterno, que mais tarde os fortaleceu para sua atividade no campo da luta social e que os conduziu para um movimento que posteriormente foi denominado como Academia do Peixe Frito.

\section{JAQUES FLORES E A ACADEMIA DO PEIXE FRITO}

A Academia do Peixe Frito foi uma organização boêmia e lúdico-cultural atuante nas décadas de 30, 40 (com desdobramentos prováveis em parte dos 50) do século XX. Integravam a Academia, além de Jaques Flores: Bruno de Menezes, líder da troupe, Abguar Bastos, De Campos Ribeiro, Rodrigues Pinagé, Paulo Oliveira, e esporadicamente, Nunes Pereira e Dalcídio Jurandir; Vicente Salles, o mais novo de todos. Embora não seja arrolado entre os acadêmicos, Tó Teixeira exerceu, junto a Bruno de Menezes, papel fundamental para que o poeta de Batuque se iniciasse nos modernistas franceses e nas tradições culturais e boêmias de parte das periferias de Belém, como o Umarizal, naquele tempo o bairro dos pretos de Belém:

Esses "moços", quase todos negros e de situação social bem diferente da dos filhos abastados da Era da Borracha, mudam o cenário social da província e trazem para o mapa cultural e, sobretudo literário e jornalístico de Belém, nos anos 30, e 40 grandes novidades deflagradas na década de 20. (...) O cenário "chic" de Belém e seus cafés à parisiense, cedem lugar a um espaço simbólico por excelência, o Ver-O-Peso. NUNES; TORRES, 2017.

A Academia do Peixe Frito foi um encontro de amigos, jornalistas, literatos, pesquisadores da cultura, que não apenas observavam a realidade da capital Belém, mas optaram por discutir sobre e escrever sobre ela, graças à consciência que tinham

VOL. 15 | N.1 | JUL. 2018 ISSN 1415-7950 
dos problemas sociais e culturais de sua época e de como o Jornalismo e a Literatura poderiam constituir suas trincheiras de resistência. Os intelectuais acadêmicos escolheram espaço físico do Ver-O- Peso, para, a partir dali, demarcar sua ação de resistência e inovação dos padrões culturais desgastados e ultrapassados, haja vista ser este um espaço aberto a todas as classes sociais e todos os tipos humanos. Jaques Flores integrou a Academia do Peixe Frito, sendo um dos escritores que dá voz a essas vozes da periferia,

Quem acompanhou Jaques na sua trajetória vê que ele não muda. Mas se mudar deixa de ser Jaques, perde a sua suprema caracteristica de contador simplório sempre misturado ao povo de sua cidade, ao povo do Ver-O-Peso, do Umarizal, do Guamá, de Barcarena. É um contista do povo e a sua linguagem é ainda a linguagem do povo. (acervo de Marcos Valério Reis, sem data e origem especificada)

Jaques conhecia os assuntos de que tratava em seus textos; seu modo de narrar é atravessado de sua experiência, de quem teve uma infância pobre e que teve de iniciar cedo no mundo do trabalho para ajudar a sustentar a família, após a perda do pai. Jaques optou, assim como os demais acadêmicos do Peixe Frito, a voltar seu olhar para a periferia e não para as luzes dos salões da Era da Borracha; ele optou por narrar as necessidades e experiências do povo amazônida e fez das histórias do povo, suas crenças, lendas e costumes sua fonte de inspiração e luta.

\section{AS OBRAS DE JAQUES}

Como já citado anteriormente, Luís Teixeira Gomes começou a trabalhar cedo e seu primeiro trabalho como tipógrafo foi o que o colocou diante do mundo do jornalismo, carreira que abraçou para toda a sua vida.

Jaques Flores produziu uma vasta obra jornalística, tornando-se autor de diversas matérias; ele desenvolveu, com grande competência o gosto por escrever crônicas, que dizia ser o "mel da cana" do universo da escrita.

Luis Teixeira Gomes foi funcionário da Policia Civil, onde atuou por mais de trinta anos. Dentre suas obras literárias, iniciou-se com Berimbau e Gaita (1925), classificada como poesia humorística. Esta recebeu elogios da crítica da época, dentre elas destaque-se a de Vicente Abranches que afirmou que "da geração nova de intelectuais do Pará, da geração que ainda não fez tolices na política nem na administração pública, o poeta Jaques Flores é, sem favor, o maior ironista do bando deleitável". Mas sua verve poética expressou-se grandemente quando escreveu Cuia Pitinga (1936), poesia, que foi livro muito elogiado pela crítica de seu tempo e sobre o qual Bruno de Menezes produziu um significativo estudo literário sob o nome de "Á margem do Cuia Pitinga".

Bruno de Menezes, segundo Georgenor Franco, (acervo Marcos Valério, sem data e origem especificada), afirmou que "No Cuia Pitinga entesta-se o problema da existência quase anfíbia do caboclo paraense . Com o Cuia Pitinga, Jaques Flores coloca-se ao nível de Lima Barreto. E concluiu: "Deve-se considerar em plano definitivamente olímpico o dom poético e sóbrio equilíbrio estético de Jaques flores. O seu lirismo é bem nosso, com acentuada predileção pelos assuntos folclóricos da planície.

Certa vez, em 1955, provocado por Jurandir Bezerra, (segundo depoimento de Georgenor Franco), Jaques respondeu, ao ser perguntado como havia começado a escrever versos":

VOL. 15 | N.1 | JUL. 2018 ISSN 1415-7950
A coisa começou como coceira em corpo de qualquer cidadão. À toa. À toa. Quando dei por mim, estava escrevendo versos. Com entusiasmo. A verdade é que esse entusiasmo está arrefecendo. $O$ verso é sonho. E eu, nesses dias de chucro materialismo, apegado às complicações da vida, vejo o sonho por um óculo. Lamentavelmente não mais posso sonhar (acervo. Marcos Valério Reis, sem data e origem especificada). 
E Jaques Flores, para nosso deleite, seguiu sonhando e produzindo obras muito importantes. Em 1942, ele escreveu "Vespasiano Ramos em sua obra" ensaio, apresentado por Francisco Paulo do Nascimento Mendes, que ressaltou o aspecto humorístico da obra, um dos traços característicos do temperamento artístico e intelectual de Jaques Flores.

Em 1944, Jaques Flores, já bem distante do espírito contestador e revolucionário da Academia do Peixe Frito, foi eleito sócio efetivo e perpétuo da Academia Paraense de Letras, atuando em vários cargos da Academia, sendo um dos mais recorrentes o cargo de tesoureiro, função, que segundo Georgenor Franco, exerceu com rigorosa honestidade. Em 1947, já experimentado na A.P.L., Jaques lançou Panela de Barro, livro de crônicas. Postumamente, em 1993, CEJUP, editora sediada em Belém, lança Obras Escolhidas de Jaques Flores.

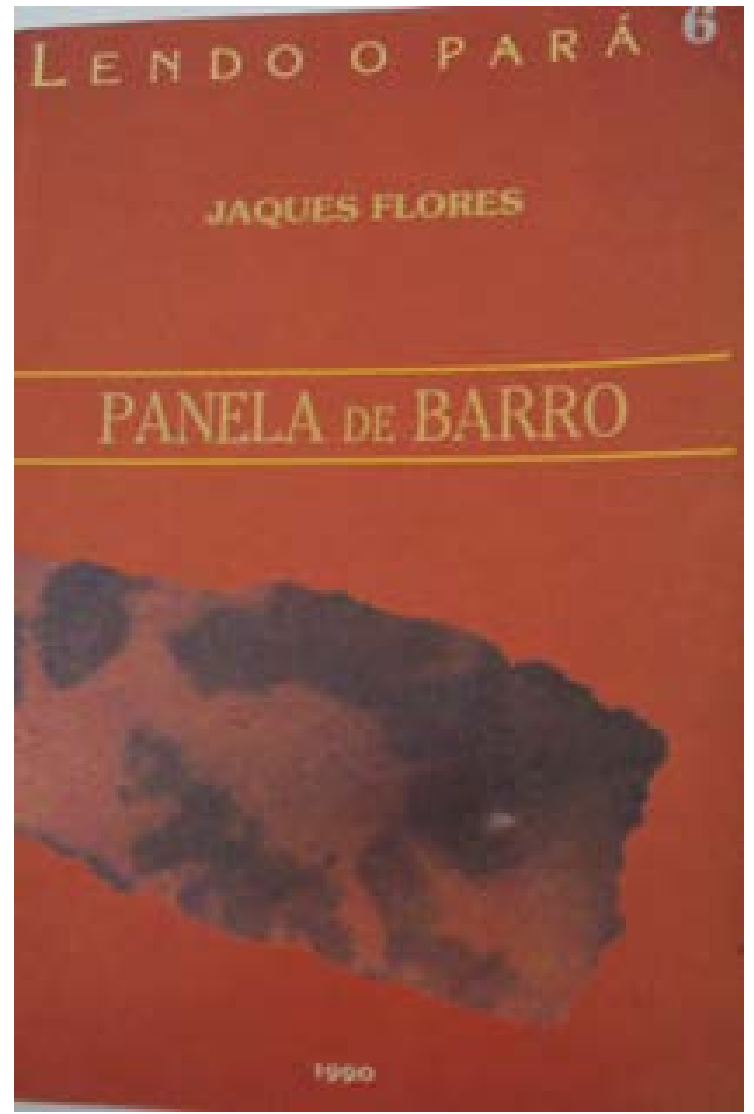

Fig. 2. 2a . Edição, projeto Lendo o Pará, 1990, sob a coordenação de Vicente Salles.

\section{SOBRE “PANELA DE BARRO”A NARRATIVA DE JAQUES FLORES}

Salvo engano, Panela de Barro tornou-se o mais expressivo livro de Jaques Flores, sobretudo depois que o professor Vicente Salles o incluiu na lista de livros do projeto Lendo o Pará, que visava a construção de uma biblioteca básica da cultura da Amazônia paraense ${ }^{1}$. No introito da obra, lê-se:

Panela de barro é o nome deste livro, o povo sabe bem o que vale e para que serve uma panela de barro. Também sabe de sua fragilidade quando se encontra com as panelas ferro, porque as panelas de barro do povo estão sempre ameaçadas pelas panelas de ferro de seus exploradores. Mas na panela de barro o povo ferve o seu alimento. Jaques pegou a panela de barro do povo para cozinhar seus "casos", suas noticias, suas lendas (...) $12^{\mathrm{a}}$. Edição, projeto Lendo o Pará, 1990, sob a coordenação de Vicente Salles. Foi um projeto de extrema importância por reeditar obras literárias de grandes autores da Literatura paraense. 
"Panela de Barro, o título já mostra seu pendor popular para o Brasil de então, é constituído de "crônicas, ensaios e fantasias", como o próprio texto esclarece, foi lançado em 1947, certamente fruto da semeadura da vivência de Jaques na Academia do Peixe Frito, é, basicamente, um livro de crônicas; são ao todo trinta e quatro narrativas, que tratam dos mais variados temas do cotidiano da região Norte, mostrando a vida social, política, literária, os gostos culinários, as lendas e as crenças do povo paraense.

Jaques Flores trata os temas com o humor que lhe é peculiar, mostrando-se um grande observador da vida amazônica, ele escreve com uma linguagem leve, clara, fluente, saborosa, como os alimentos que são cozidos na panela a que o título do livro refere-se. Sua escrita reforça o que sobre ele comentou Abguar Bastos, isto é, Jaques Flores era um Maranduêra, um guardador das tradições e um narrador fluente, o que nos remete à Walter Benjamim quando explana acerca dos dois tipos de narradores que marcam a obra de Lescov. Utilizando-se das possibilidades da crônica, que mistura realidade e ficção, o autor, muitas vezes investido de narrador de suas histórias, é aquele que conhece bem sua terra e afirma que escutamos com prazer o homem que viveu intensamente sua vida sem sair do seu chão e que, talvez por isto, treinado na experimentação de valorização popular da Academia do Peixe Frito, conhece e honra as suas histórias e tradições. Assim, em Panela de Barro, o narrador Jaques Flores conta as histórias que ouviu ou viu acontecer em sua época, atribuindo-lhes o tempero próprio, com humor e leveza.

Fig. 3. Andersen Editores. Rio de janeiro, 1947

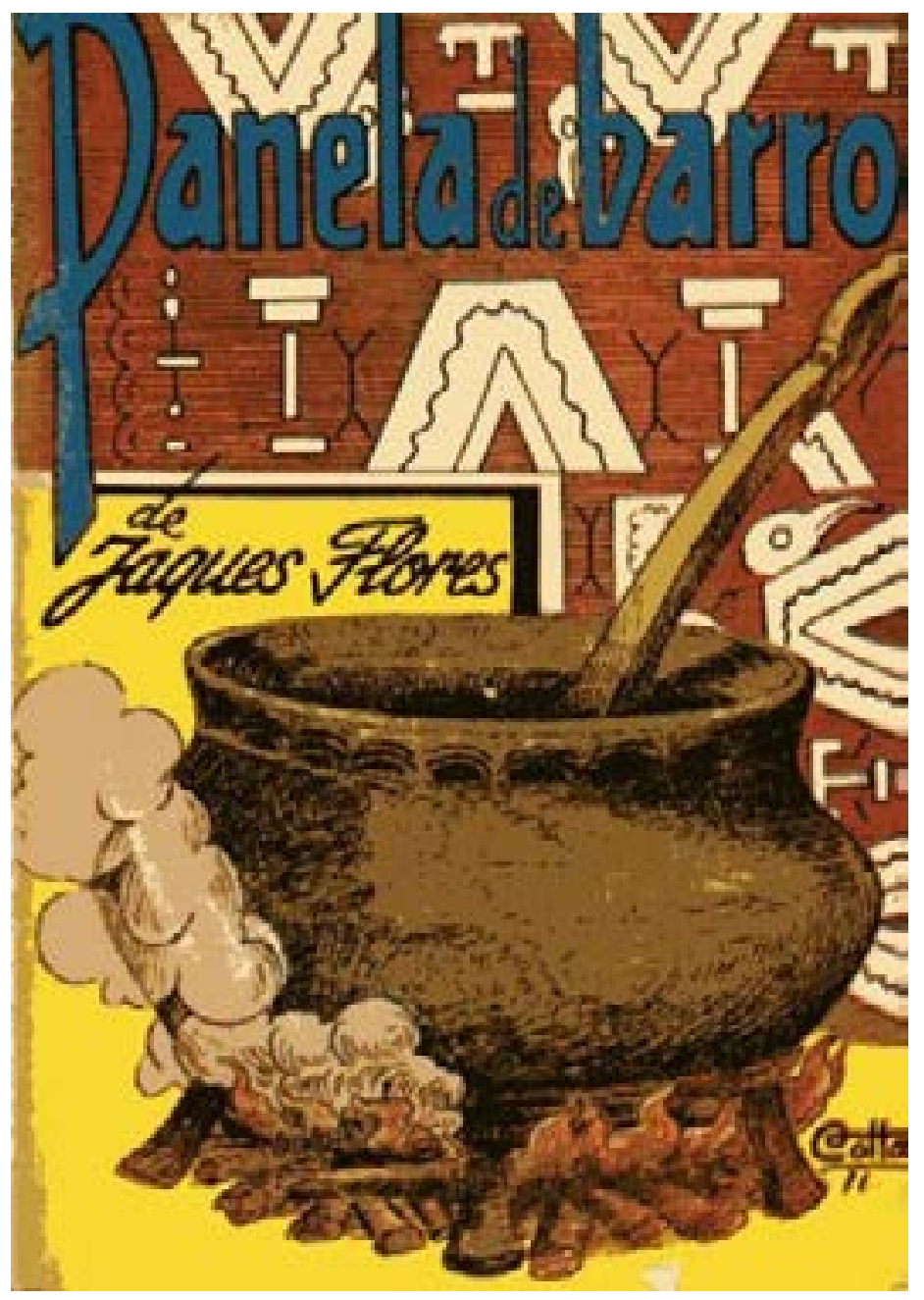




\section{CONVITE ESPECIAL: "VAMOS COMER PEIXE FRITO?"}

Esta crônica, especial para nós que vivenciamos a experiência da Academia do Peixe Frito, mostra um traço característico dos paraenses de algumas regiões do Estado nos idos da década de cinquenta, o hábito de comer peixe frito, costume que é um marco da gente humilde das periferias de Belém (embora nem só os mais pobres deem preferência a este prato). Jaques inicia sua crônica instigando o leitor a pensar na culinária, no "material de boca" como uma das características do modo de vida das cidades e afirma "que o peixe frito constitui uma das características da alimentação da massa popular de Belém” (pág.123, 1947). Ele leva o leitor a um passeio pela cidade e apresenta a iguaria que, à sua época, podia ser comprada nas quitandas dos bairros da periferia da cidade com a maior facilidade; relata também que o peixe frito acompanhou o progresso e passou a ser encontrado nas mesa dos hotéis, cafés e locais "chics" do centro de Belém. Ele, no entanto, ressalta que o lugar preferido para se consumir um bom peixe frito é o mercado e demonstra ser um conhecedor de todos os mercados da cidade de Belém e afirma que quando "não se veem vendedores de peixe frito é, que o negócio está mais que vasqueiro, está vasqueiríssimo. (FLORES, pág. 154)

Como bom observador da realidade, o cronista Jaques Flores, marcado certamente pela experiência do jornalista, não deixou passar despercebida a crise do pescado enfrentada na capital, na qual o paraense, para não perder seu prato ferido, mudou o tipo de peixe consumido: substituindo a tainha pela piramutaba.

Sendo frequentador dos mercados, Jaques podia observar todos os tipos humanos que por ali passavam, gente de todas as classes sociais que iam comprar o precioso alimento. Os compradores iam desde a gente humilde aos engravatados e às senhoras da sociedade que iam comprar a iguaria. Sobre uma de suas visitas ao mercado do Ver- o - Peso relatou que:

(...) não aparecia só gente de pé no chão e camisa de meia ou blusa suja não! Vi muitos camadas de gravata, desses metidos a sebo, comprando as suas postas, naturalmente para melhorar o almoço ou mesmo para constituir o dito. Quem sabe lá da vida dos outros?... Vi uma dona Chancha, de lábios pintados e toda no chique, comprar 20 postas, para cujo o embrulho trouxe um papel especial dentro da bolsa cara (FLORES, 1947).

A narrativa é finalizada com um convite de dar água na boca do leitor, paraense ou não, para, depois de ter tomado um gole da "pura dona Branca", para abrir o apetite, comer um peixe frito "de estalar a língua" acompanhado de farinha, molho de pimenta e limão.

\section{SOBRE NÃO DEIXAR JAQUES FLOES CAIR NO ESQUECIMENTO}

Luis Teixeira Gomes, o Jaques Flores, foi um exímio cantador/contador das coisas de seu tempo; um jornalista engajado, sensível, atento; um trabalhador das letras, um "leitor" das pessoas e do mundo que o circundava. A leitura de Panela de Barro proporciona um mergulho na sociedade paraense das primeiras décadas do século XX.

A linguagem do narrador que percorria a cidade, que conversava com as pessoas no Ver- o- Peso e que, acima de tudo, vivia a cidade e sua realidade e que buscava, no toque de humor dado à sua escrita, retratar a cultura e os costumes sociais do paraense de seu tempo. Ler Jaques Flores, ler sua narrativa, é percorrer as ruas, os mercados, as periferias, os espaços de boemia, é conhecer Belém e seu povo, é voltar os olhos para a periferia que as elites conservadoras tentam silenciar.

Conhecer Jaques Flores é ter contato com sua trajetória de muito trabalho e contribuição para o jornalismo e para a Literatura. Estudar Jaques Flores e sua obra, sua participação na Academia do Peixe Frito (objetivo a que me proponho a fazer a partir de então, em estudos futuros) faz-se urgente, pois assim não permitiremos que

VOL. 15 | N.1 | JUL. 2018 ISSN 1415-7950

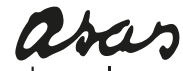

da palavra 
sua voz e as vozes que ele representa em suas narrativas, sejam silenciadas.

Como disse certa vez o professor Francisco Paulo Mendes, (segundo Georgenor Franco), debruçar-se sobre a escrita de Jaques Flores é "um dos nossos deveres, dever dos novos, é tirar do esquecimento e reabilitar a herança literária da Poesia" da poesia e da prosa que está elencada no instigante Panela de Barro, com o qual o peixe passou não somente a ser frito, mas cozido pelo olhar investigador de novos leitores.

\section{REFERÊNCIAS}

BASTOS, Abguar. A panela vai ferver, In: FLORES, Jaques (Luis Teixeira Gomes). Panela de Barro. Crônicas, ensaios, fantasias. Andersen Editores. Rio de Janeiro, 1947.

BENJAMIN, W. O narrador: considerações sobre a obra de Nikolai Leskov. In: BENJAMIN, W. Magia e técnica, arte e política: ensaios sobre literatura e história da cultura. São Paulo: Brasiliense, 1987.

FLORES, Jaques. Panela de Barro. Crônicas, ensaios, fantasias. Andersen Editores. Rio de janeiro, 1947.

FRANCO, Georgenor. Luis Teixeira Gomes: se mudasse, deixaria de ser Jaques Flores (acervo Marcos Valério, sem data e origem especificada).

NUNES e TORRES. Academia do Peixe Frito: diálogos e intersecções entre Literatura, jornalismo e Ciências Sociais na Amazônia do século XX. ANAPCOS : 2016 NUNES, Paulo; TORRES, Vânia. Apresentação do Projeto Academia do Peixe Frito. Belém, 2017. Para o evento da "I Fritação do Peixe" Painel de estudos do projeto de pesquisa Academia do peixe Frito: interfaces entre literatura e Jornalismo, que ocorreu em novembro de 2017 na Universidade da Amazônia em Belém. 